\title{
Sex Differences in Medication and Primary Healthcare Use before and after Spousal Bereavement at Older Ages in Denmark: Nationwide Register Study of over 6000 Bereavements
}

\author{
Anna Oksuzyan, ${ }^{1,2}$ Rune Jacobsen, ${ }^{1}$ Karen Glaser, ${ }^{3}$ Cecilia Tomassini, ${ }^{4,5}$ \\ James W. Vaupel, ${ }^{2}$ and Kaare Christensen ${ }^{1,6,7}$ \\ ${ }^{1}$ The Danish Aging Research Center, Institute of Public Health, University of Southern Denmark, \\ J. B. Winsloews Vej 9B, 5000 Odense, Denmark \\ ${ }^{2}$ Laboratory of Survival and Longevity, Max Planck Institute for Demographic Research, Konrad-Zuse Street 1, 18057 Rostock, Germany \\ ${ }^{3}$ Institute of Gerontology, King's College London, Melbourne House, Strand, London WC2R 2LS, UK \\ ${ }^{4}$ Department SEGES, University of Molise, Via F. De Sanctis, 86100 Campobasso, Italy \\ ${ }^{5}$ Population Studies Department, London School of Hygiene and Tropical Medicine, Keppel Street, London WC1E 7HT, UK \\ ${ }^{6}$ The Danish Twin Registry, University of Southern Denmark, J. B. Winsloews Vej 9, 5000 Odense, Denmark \\ ${ }^{7}$ Department of Clinical Biochemistry and Pharmacology and Department of Clinical Genetics, Odense University Hospital, \\ Soender Boulevard 29, 5000 Odense, Denmark
}

Correspondence should be addressed to Anna Oksuzyan, aoksuzyan@health.sdu.dk

Received 11 March 2011; Revised 10 June 2011; Accepted 21 June 2011

Academic Editor: Kee Lee Chou

Copyright ( 12011 Anna Oksuzyan et al. This is an open access article distributed under the Creative Commons Attribution License, which permits unrestricted use, distribution, and reproduction in any medium, provided the original work is properly cited.

\begin{abstract}
Background. The study aimed to examine sex differences in healthcare use before and after widowhood to investigate whether reduced healthcare use among widowers compared with widows may partially explain excess mortality and more adverse health outcomes among men than women after spousal loss. Methods. All individuals alive and aged at least 60 years in 1996 and who became widowed in the period from 1996 to 2003 were selected from the 5\% sample of the total Danish population and all Danish twins. The healthcare use was assessed as the average daily all-cause and major system-specific medication use and the average annual number of visits to general physicians (GPs). Results. The average daily use of all-cause and major system-specific medications, as well as the number of GP visits increased over the period from 1 year before and up to 5 years after a spouse's death, but there were no sex-specific patterns in the trajectories of medication use and number of GP visits after conjugal loss. Conclusion. We found little support for the hypothesis that reduced healthcare use contributes to the explanation of more adverse health outcomes after conjugal loss in men compared with women in Denmark.
\end{abstract}

\section{Introduction}

There is a mounting research literature showing a mortality and health disadvantage after spousal bereavement [1]. Elevated risks of death after conjugal loss among middleand old-aged persons were found for all-cause mortality and most major causes of death, such as cancers, cardiovascular diseases (CVD), respiratory diseases, accidents, and violence in Finland, UK, and the US [2-5]. This excess mortality among the bereaved usually occurs within the first six months following the death of a spouse $[3,4]$; however, some studies have suggested that it remains high many years after bereavement $[6,7]$. In addition to mortality, the loss of a spouse was found to be associated with higher levels of depressive symptoms, poorer physical and cognitive function, worse self-rated health, and an increased risk of institutionalization in the US, Chinese, and Finish middleand old-aged surviving spouses [8-12]. The adverse effects 
of spousal loss on health and mortality were independent of socioeconomic and health characteristics [8, 10, 13].

Previous research has shown significant sex differences in the widowhood effects: greater adverse effects on mortality and health have been found among widowers $[1,3,9,10$, $14,15]$. Nevertheless, a few studies reported excess all-cause mortality after spousal loss to be very similar in men and women $[6,16]$. There is also conflicting evidence regarding sex differences in the effects of bereavement on depressive symptoms and other dimensions of mental health [12, 14, 17].

Although the literature on widowhood effects on health and mortality in Denmark is limited, available data suggest that, as in the predominantly North American literature, the excess mortality is substantially higher among middle-aged and elderly widowers than among the same-aged widows [7, $18,19]$. A register study among the total Danish population aged 50 and over found that the oldest-old widowers had substantially higher suicide risks than the same-aged widows, but the sex differences were less pronounced in the younger age groups [7]. However, another register-based study in Denmark among 25-60 years old individuals revealed that the relative risk of suicide and risk of death from other causes after conjugal loss was substantially higher in men than in women. A study based on the total Danish twin population aged 50 to 70 indicated higher hazard rates after the death of a spouse and co-twin among men than among women, although the timing patterns were similar in both sexes [19]. Evidence for sex differences in widowhood effects on cancer incidence and cancer mortality in other Scandinavian countries is inconclusive $[20,21]$. Although cancer incidence changed in the same direction among Swedish widowers and widows, the risk of esophageal, lung, and all cancers was higher in men than in women, whereas the risk of pancreatic cancer significantly increased and the risk of melanoma, skin, cancer and non-Hodgkin's disease significantly decreased in women only [20].

Several explanations have been proposed for gender differences in health and morality following bereavement. First, as most studies have generally demonstrated greater longevity and health benefits for married men than for married women, it has been suggested that conjugal loss may be more stressful for widowers compared with widows [15]. However, it is still unclear why physiological changes underlying reactivity to stressful life events should differ by sex. Second, it has been suggested that the adverse effects of widowhood on health and mortality may be due to the loss of social, material, and task support [3, 15]. Finally, there has been some investigation of the impact of losing a spouse on health behaviors, such as smoking, alcohol consumption, diet, and interaction with healthcare services [22-26].

Despite growing research on the adverse widowhood effects on health and mortality, existing studies that examined sex differences in lifestyle behaviors and social assistance as explanations for sex differential effect of widowhood on health and mortality had small sample size [23, 25, 27, 28], short follow-up period [29], excluded old-aged individuals [24], had no information on nonrespondents [9], and were based on cross-sectional data [30]. Studies on the changes in health maintaining behavior around the time of widowhood as underlying mechanism for adverse bereavement effect on health and mortality are scarce $[26,31]$.

The present study aimed to investigate sex differences in short- and longer-term healthcare use following conjugal loss by comparing medication and primary healthcare use before and after a spouse's death. We hypothesized that after a spouse's death elderly men will reduce medication use and visits to general practitioners (GPs), while women will maintain or increase their healthcare utilization compared to their preloss level. If so, such reduction in medication use and number of GP visits among men may contribute to the explanation of more adverse health outcomes after conjugal loss among men than women.

\section{Materials and Methods}

In April 1968, the Civil Registration System (CRS) was introduced in Denmark, where each resident is assigned the 10-digit unique personal identifier, the Central Personal Register (CPR) number. The CPR-number was used to link the diverse computerized registers covering the total Danish population: Danish Demographic Database (DDB) (demographics, residence, migration, and civil status since 1968), the Prescription Medicine Register (medicine-related information since 1995), the Health Insurance Register (information on primary care services since 1997), and the Danish Twins Register (demographics, residency, zygosity). Prior studies have proved the register data in Denmark to be reliable and valid with no linkage problems among registers [32-34].

The study is based on the 5\% sample of the total Danish population and all Danish twins identified through the CRS and the Danish Twin Register, respectively. The total twin population was included to increase the sample size of older people, especially men, who became widowed in the period from January 1, 1996 to January 31, 2003. Previous research in Denmark demonstrated that twins are representative of general populations in terms of health trajectories, psychological function, and all-cause and cardiovascular mortality and, thus, are good population models for epidemiological and demographic research $[35,36]$. Additionally, the analysis of age-specific death rates in the twin and 5\% population by marital status in 1998 and 2000 showed patterns similar to that in the total Danish population (data not shown).

All individuals alive and aged at least 60 years by January 1, 1996 were initially selected. Further we selected all individuals who became widowed in the period from January 1, 1996 to January 31, 2003. This observation period was chosen as the Prescription Medicine Register is only available from 1995 onwards, and the updated civil status was available until January 31, 2003. Furthermore, the analysis of primary healthcare use was restricted to the period from January 1, 1997 to January 31, 2003 because the Health Insurance Register only began in 1997. Survival status was available through December 2006.

The Prescription Medicine Register contains detailed Anatomical Therapeutic Chemical classification system (ATC) codes of prescribed medications and their sublevels, 
TABLE 1: The frequency of all-cause and system-specific medication use within 1 year before and 1 year after widowhood.

\begin{tabular}{|c|c|c|c|c|c|c|c|c|c|c|c|}
\hline \multirow{3}{*}{ ATC } & \multirow{3}{*}{ Age } & \multirow{3}{*}{ Men No. } & \multirow{3}{*}{ Women No. } & \multicolumn{4}{|c|}{ Users before } & \multicolumn{4}{|c|}{ Users after } \\
\hline & & & & \multicolumn{2}{|c|}{ Men } & \multicolumn{2}{|c|}{ Women } & \multicolumn{2}{|c|}{ Men } & \multicolumn{2}{|c|}{ Women } \\
\hline & & & & No. & $\%$ & No. & $\%$ & No. & $\%$ & No. & $\%$ \\
\hline \multirow{3}{*}{ All-cause } & $60-69$ & 521 & 1242 & 416 & 79.8 & 1022 & 82.3 & 418 & $80.2^{\ddagger}$ & 1081 & 87.0 \\
\hline & $70-79$ & 925 & 1996 & 771 & $83.4^{\dagger}$ & 1777 & 89.0 & 807 & $87.2^{\ddagger}$ & 1837 & 92.0 \\
\hline & $80+$ & 707 & 1030 & 619 & $87.6^{\dagger}$ & 946 & 91.8 & 644 & $91.1^{\ddagger}$ & 975 & 94.7 \\
\hline \multirow{3}{*}{ ATC-C } & $60-69$ & 521 & 1242 & 166 & 31.9 & 435 & 35.0 & 204 & 39.2 & 488 & 39.3 \\
\hline & $70-79$ & 925 & 1996 & 399 & $43.1^{\dagger}$ & 992 & 49.7 & 451 & $48.8^{\ddagger}$ & 1098 & 55.0 \\
\hline & $80+$ & 707 & 1030 & 387 & $54.8^{\dagger}$ & 629 & 61.1 & 431 & 61.0 & 653 & 63.4 \\
\hline \multirow{3}{*}{ ATC-N } & $60-69$ & 521 & 1242 & 210 & $40.3^{\dagger}$ & 594 & 47.8 & 253 & $48.6^{\ddagger}$ & 768 & 61.8 \\
\hline & $70-79$ & 925 & 1996 & 414 & $44.8^{\dagger}$ & 1204 & 60.3 & 508 & $54.9^{\ddagger}$ & 1367 & 68.5 \\
\hline & $80+$ & 707 & 1030 & 399 & $56.4^{\dagger}$ & 715 & 69.4 & 454 & $64.2^{\ddagger}$ & 783 & 76.0 \\
\hline \multirow{3}{*}{ ATC-R } & $60-69$ & 521 & 1242 & 102 & $19.6^{\dagger}$ & 299 & 24.1 & 113 & 21.7 & 315 & 25.4 \\
\hline & $70-79$ & 925 & 1996 & 207 & $22.4^{\dagger}$ & 526 & 26.4 & 217 & $23.5^{\ddagger}$ & 566 & 28.4 \\
\hline & $80+$ & 707 & 1030 & 177 & 25.0 & 255 & 24.8 & 192 & 27.2 & 266 & 25.8 \\
\hline \multirow{3}{*}{ ATC-A } & $60-69$ & 521 & 1242 & 129 & 24.8 & 338 & 27.2 & 158 & 30.3 & 353 & 28.4 \\
\hline & $70-79$ & 925 & 1996 & 284 & $30.7^{\dagger}$ & 709 & 35.5 & 333 & 36.0 & 772 & 38.7 \\
\hline & $80+$ & 707 & 1030 & 292 & 41.3 & 461 & 44.8 & 342 & 48.4 & 497 & 48.3 \\
\hline
\end{tabular}

ATC: Anatomical Therapeutic Chemical classification system; ATC-C: cardiovascular system; ATC-N: nervous system; ACT-R: respiratory system; ATC-A: alimentary tract and metabolism medications.

${ }^{\dagger} P$ value $<0.05$ for sex difference in the frequency of medication use before widowhood as obtained by chi-square test.

${ }^{\ddagger} P$ value $<0.05$ for sex difference in the frequency of medication use after widowhood as obtained by chi-square test.

dates of purchase, daily defined dose (DDD), and other drugrelated information. The defined daily dose of a medication is based on the accepted average dose per 24 hours for that medicinal product facilitating comparison of consumption across different medications [37]. All-cause medication use was estimated within 1 year before and up to 5 years after spousal death in the average daily defined dose (DDD) by dividing the total DDDs dispensed for all medications combined within 1 year to 365.25 days. If a surviving spouse died within a follow-up year, the average DDD was calculated by dividing the total DDD dispensed during that followup year to the number of days survived. Because previous studies showed sex differences in cause-specific medication use, the medication use was also assessed for several major system-specific medications (the anatomical main group level 1): cardiovascular (ATC-C), nervous (ATC-N), respiratory (ATC-R), and alimentary tract and metabolism (ATC-A) medications.

The use of primary healthcare was assessed as the average number of visits to GPs per year within 1 year before and up to 4 years after spouse's death. Similar to the estimation of medication use, the average number of GP visits in the follow-up years was adjusted to the time at risk. Additional analyses of all-cause and system-specific medication use before and after widowhood among individuals conditional on their survival to the third and fifth follow-up years were conducted to investigate whether selective dropout due to death has an effect on the trajectories of healthcare use. The age at widowhood was categorized into three groups to avoid small number of users in each age group: 60-69, $70-79$, and $80+$ years. Data analysis was performed using Intercooled Stata 10.0. Chi-square tests were used to examine sex differences in the prevalence of medication use and two independent sample $t$-tests were used to examine sex differences in the average medication use and number of GP visits 1 year before and 1 year after widowhood and the sex gap in the change of healthcare use over the two time points.

\section{Results}

In total, there were 6421 individuals (66.5\% women) aged at least 60 by January, 1996 and became widowed during the observation period from January 1, 1996 to January 31, 2003. Table 1 presents the percentage of men and women taking prescription medications 1 year before and 1 year after widowhood. In general, all-cause and system-specific medication use 1 year before and 1 year after a spouse's death was more frequent among women than men (Table 1). However, there were almost no gender differences in the prevalence of ATC-A medications either one year before or after widowhood (Table 1).

Table 2 shows the average DDD for ATC medications dispensed 1 year before and after widowhood and the mean difference in the average DDD between the two time periods. Generally, the highest average DDD was found for ATC-C medications, followed by ATC-N and ATC-R medicines in both men and women. Women had higher average DDDs for all-cause and ATC-N medications compared with men in both the year before and after widowhood. Men, generally, had higher average DDDs for ATC-R medications, although sex differences were not always statistically significant. The sex-specific patterns for ATC-C and ATC-A medications were less clear (Table 2). As expected, at each cross-sectional time point, the average DDD was higher in older age groups. 
TABLE 2: Average daily defined dose of all-cause and system-specific medications dispensed within 1 year before and 1 year after widowhood.

\begin{tabular}{|c|c|c|c|c|c|c|c|c|c|c|c|c|c|}
\hline \multirow{3}{*}{ ATC } & \multirow{3}{*}{ Age } & \multicolumn{4}{|c|}{ Before } & \multicolumn{4}{|c|}{ After } & \multicolumn{4}{|c|}{ Difference $^{\S}$} \\
\hline & & \multicolumn{2}{|c|}{ Men } & \multicolumn{2}{|c|}{ Women } & \multicolumn{2}{|c|}{ Men } & \multicolumn{2}{|c|}{ Women } & \multicolumn{2}{|c|}{ Men } & \multicolumn{2}{|c|}{ Women } \\
\hline & & Mean & SE & Mean & SE & Mean & SE & Mean & SE & Mean & SE & Mean & SE \\
\hline \multirow{3}{*}{ All-cause } & 60-69 & 1.52 & 0.11 & 1.69 & 0.08 & 1.90 & 0.18 & 1.99 & 0.09 & 0.38 & 0.12 & 0.30 & 0.04 \\
\hline & $70-79$ & $1.98^{\dagger}$ & 0.09 & 2.46 & 0.07 & $2.51^{\ddagger}$ & 0.11 & 2.92 & 0.11 & 0.54 & 0.07 & 0.46 & 0.09 \\
\hline & $80+$ & 2.59 & 0.13 & 2.70 & 0.09 & 3.52 & 0.23 & 3.16 & 0.09 & $0.92^{*}$ & 0.18 & 0.46 & 0.06 \\
\hline \multirow{3}{*}{ ATC-C } & $60-69$ & 0.67 & 0.07 & 0.59 & 0.05 & 0.84 & 0.12 & 0.70 & 0.06 & 0.17 & 0.09 & 0.11 & 0.02 \\
\hline & $70-79$ & $0.82^{\dagger}$ & 0.05 & 0.95 & 0.04 & 1.08 & 0.07 & 1.11 & 0.05 & 0.25 & 0.05 & 0.15 & 0.03 \\
\hline & $80+$ & 1.09 & 0.07 & 1.11 & 0.05 & 1.48 & 0.15 & 1.24 & 0.06 & $0.39 *$ & 0.12 & 0.13 & 0.03 \\
\hline \multirow{3}{*}{ ATC-N } & $60-69$ & $0.26^{\dagger}$ & 0.03 & 0.40 & 0.02 & $0.34^{\ddagger}$ & 0.04 & 0.52 & 0.03 & 0.08 & 0.02 & 0.13 & 0.01 \\
\hline & $70-79$ & $0.32^{\dagger}$ & 0.02 & 0.55 & 0.02 & $0.43^{\ddagger}$ & 0.03 & 0.70 & 0.03 & 0.12 & 0.02 & 0.15 & 0.02 \\
\hline & $80+$ & $0.44^{\dagger}$ & 0.03 & 0.65 & 0.03 & $0.59^{\ddagger}$ & 0.04 & 0.77 & 0.03 & 0.15 & 0.03 & 0.12 & 0.02 \\
\hline \multirow{3}{*}{ ATC-R } & $60-69$ & 0.22 & 0.04 & 0.17 & 0.02 & 0.26 & 0.05 & 0.19 & 0.02 & 0.04 & 0.03 & 0.01 & 0.01 \\
\hline & $70-79$ & 0.21 & 0.03 & 0.21 & 0.02 & 0.25 & 0.03 & 0.24 & 0.02 & 0.04 & 0.01 & 0.02 & 0.01 \\
\hline & $80+$ & $0.17^{\dagger}$ & 0.02 & 0.10 & 0.01 & $0.20^{\ddagger}$ & 0.02 & 0.12 & 0.01 & 0.02 & 0.01 & 0.02 & 0.01 \\
\hline \multirow{3}{*}{ ATC-A } & $60-69$ & 0.12 & 0.02 & 0.15 & 0.01 & 0.15 & 0.02 & 0.17 & 0.01 & 0.03 & 0.02 & 0.02 & 0.01 \\
\hline & $70-79$ & 0.18 & 0.02 & 0.21 & 0.01 & 0.23 & 0.02 & 0.27 & 0.03 & 0.04 & 0.01 & 0.06 & 0.03 \\
\hline & $80+$ & 0.27 & 0.03 & 0.29 & 0.02 & 0.41 & 0.04 & 0.36 & 0.02 & $0.14^{*}$ & 0.03 & 0.07 & 0.01 \\
\hline
\end{tabular}

ATC: Anatomical Therapeutic Chemical classification system; ATC-C: cardiovascular system; ATC-N: nervous system; ACT-R: respiratory system; ATC-A: alimentary tract and metabolism medications; DDD: daily defined dose.

${ }^{*} P$ value $<0.05$ for sex differences in the change of medication use before and after widowhood as obtained by two-sided $t$-test.

${ }^{\dagger} P$ value $<0.05$ for sex difference in the average DDD before widowhood as obtained by two-sided $t$-test.

${ }^{\ddagger} P$ value $<0.05$ for sex difference in the average DDD after widowhood as obtained by two-sided $t$-test.

$\S$ Difference $=$ average DDD after, average DDD before.

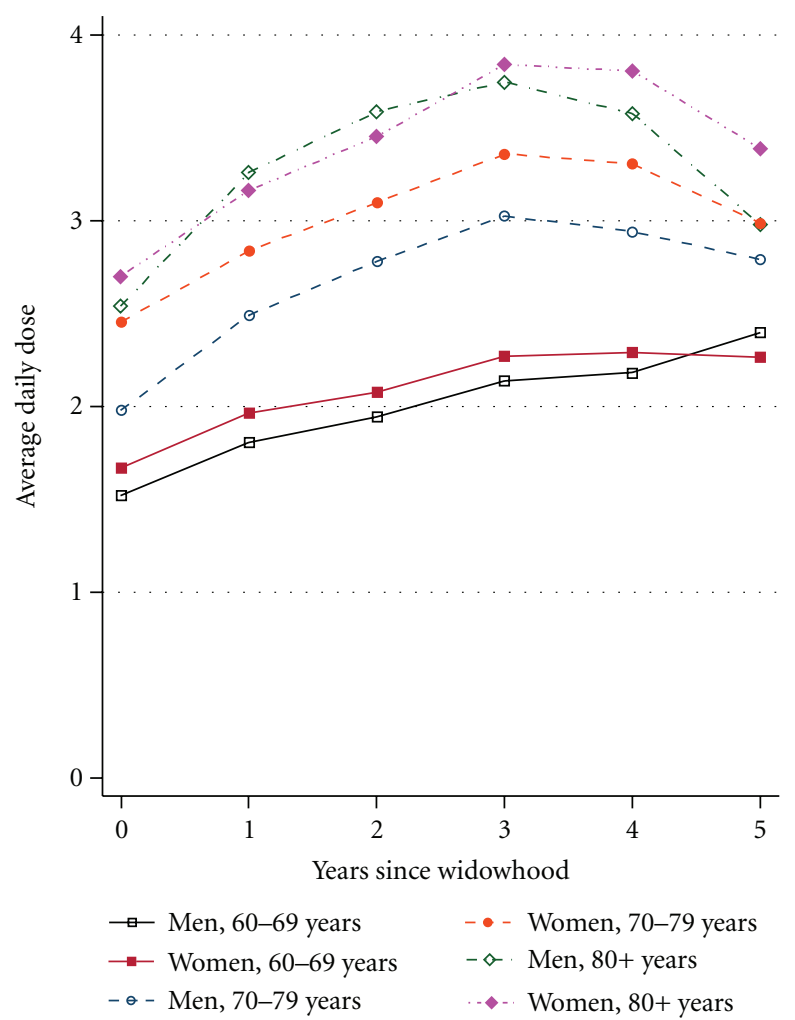

(a)

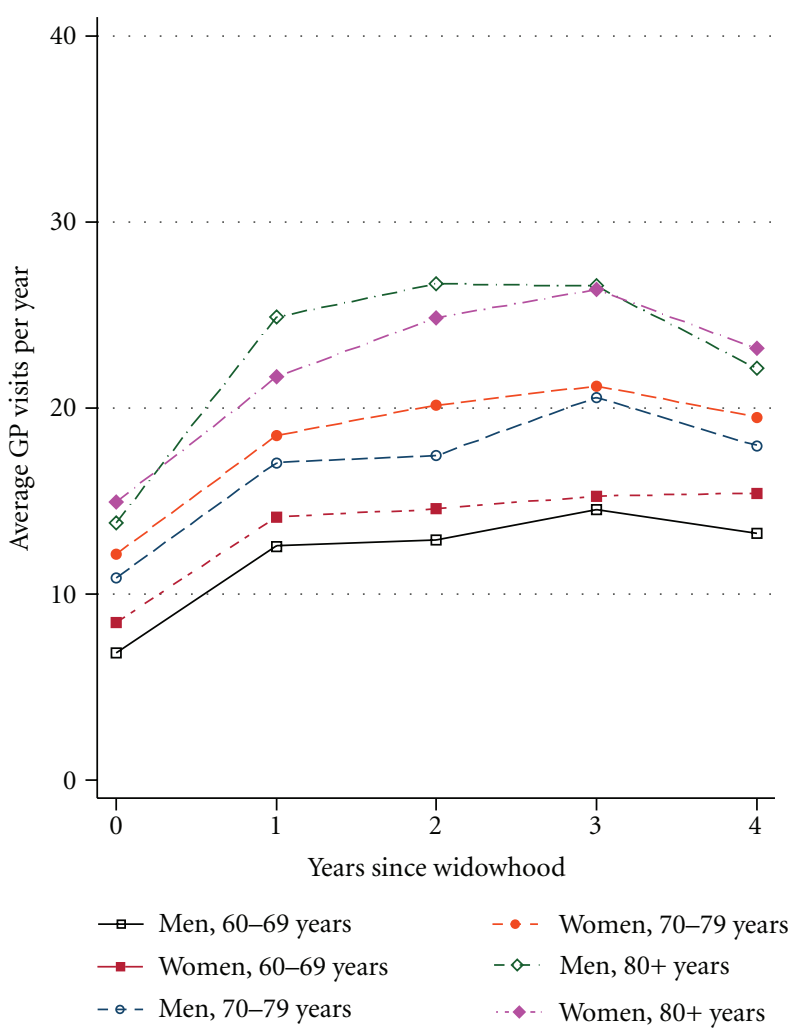

(b)

FIGURE 1: All-causes medication use and number of GP visits before and after widowhood. 


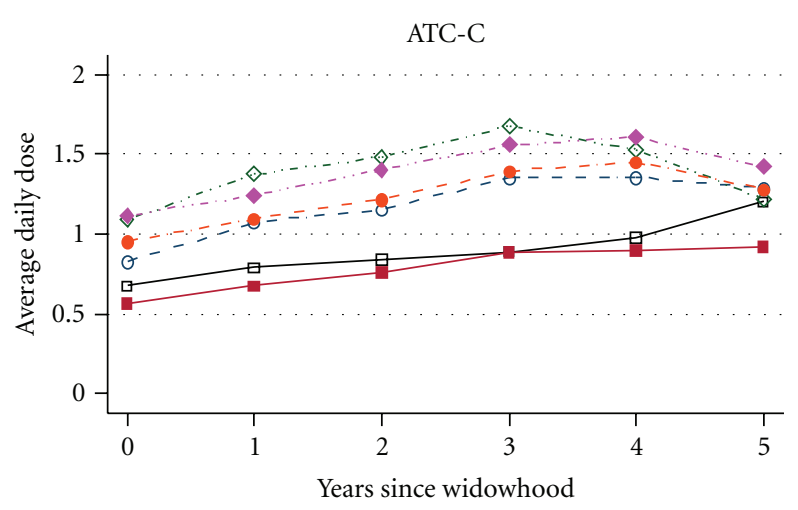

(a)

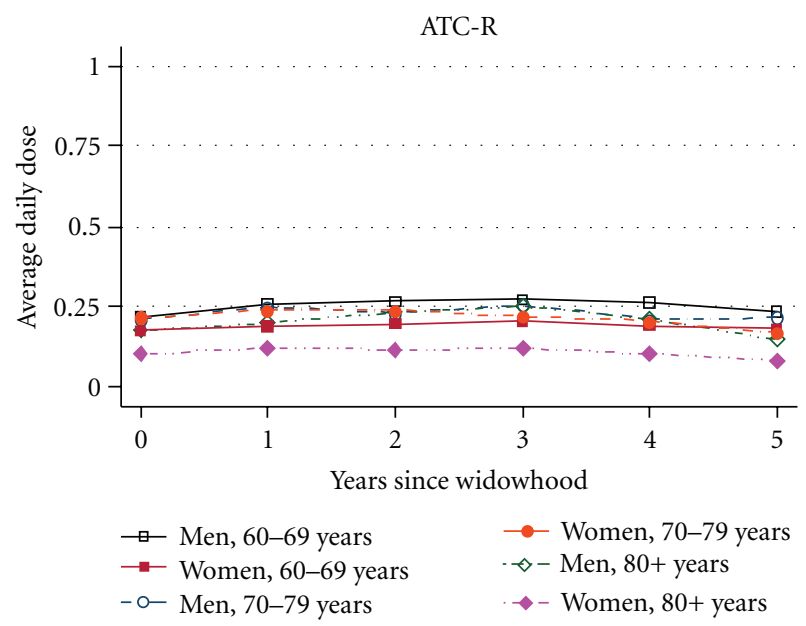

(c)

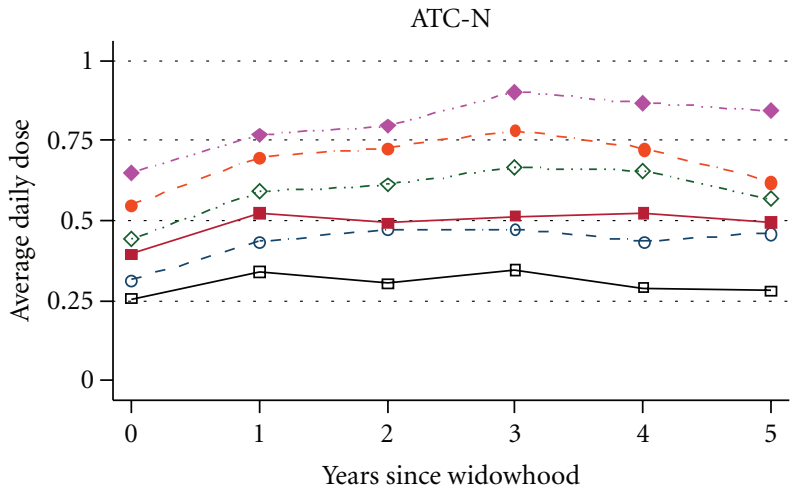

(b)

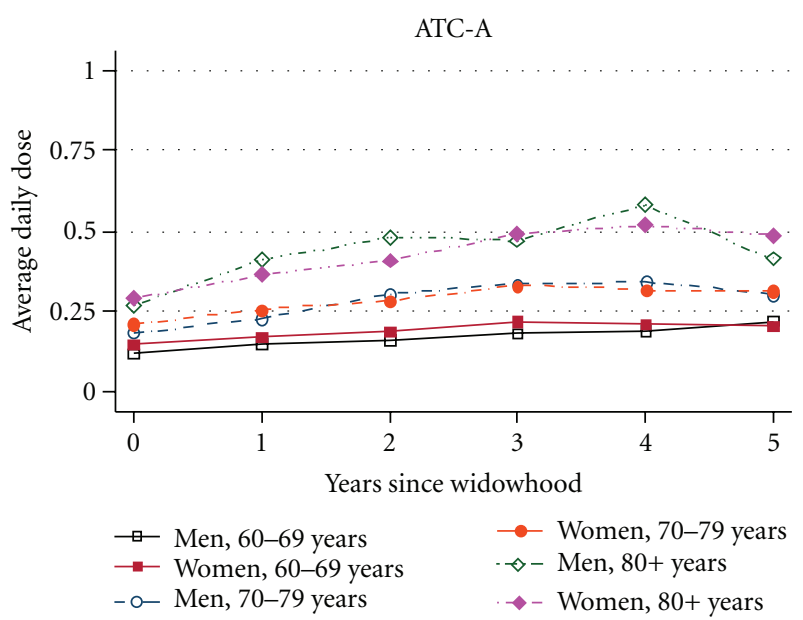

(d)

Figure 2: System-specific medication use before and after widowhood.

The average DDD for all-cause and systems-specific ATC medications increased from 1 year before to 1 year after widowhood for both men and women (Table 2). The highest increase in average DDD was observed in the ATC-C and ATC-N medication use, followed by ATC-R and ATC-A medications. The increase in all-cause, ATC-C, and ATC- $\mathrm{R}$ medication use was slightly higher in men. However, the sex difference was statistically significant in the oldest age group for all-cause $(P$-value $=0.02)$, ATC-C $(P$-value $=0.04)$, and ATC-A $(P=0.02)$ medications.

Further analysis was done to examine whether there was a sex-specific pattern in all-cause and system-specific medication use up to 5 years after conjugal loss. The average DDD for all-cause medications increased between the year before and the third or fourth year following widowhood and remained almost constant or slightly decreased afterwards (Figure 1). Similar patterns were indicated for system-specific medication use, although with much smaller variations over time (Figure 2). However, there was no sexspecific pattern in the change of all-cause and systemsspecific medication use over 1 year before and up to 5 years after widowhood. Among system-specific medications, the most pronounced changes were observed for ATC-C agents, except for the 60-69 years old age group, followed by ATC-N and ATC-A medications. The increase in the ATC-N medication use seems to be steeper within the first year after widowhood, but the pattern was similar in both sexes and all age groups. The smallest changes over the follow-up period were indicated for ATC-R medication use.

Analogous findings were obtained when the average number of GP visits per year was considered as an indicator of healthcare utilization (Figure 1). Women had slightly more GP visits in all age groups compared with men. The average number of visits increased with advancing age, but these changes were similar in men and women. Similar patterns were indicated when the median number of GP visits was considered.

To investigate whether selective dropout due to death has an effect on the trajectories of healthcare use, we analyzed all-cause and system-specific medication use and number of GP visits before and after widowhood among individuals conditional on their survival to the third and fifth follow-up years. The trajectories for all-cause (Figure 3 ) and system-specific medication use remained unchanged when the analysis was restricted to three- and five-year survivors after spousal loss. Also, these results remained 


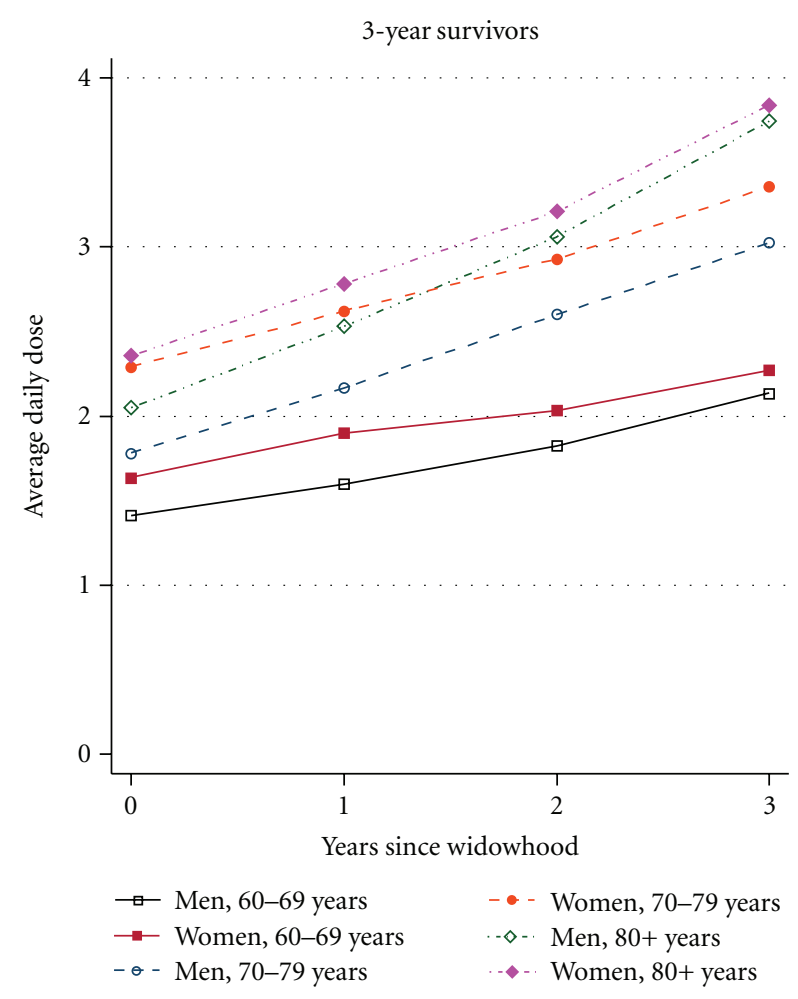

(a)

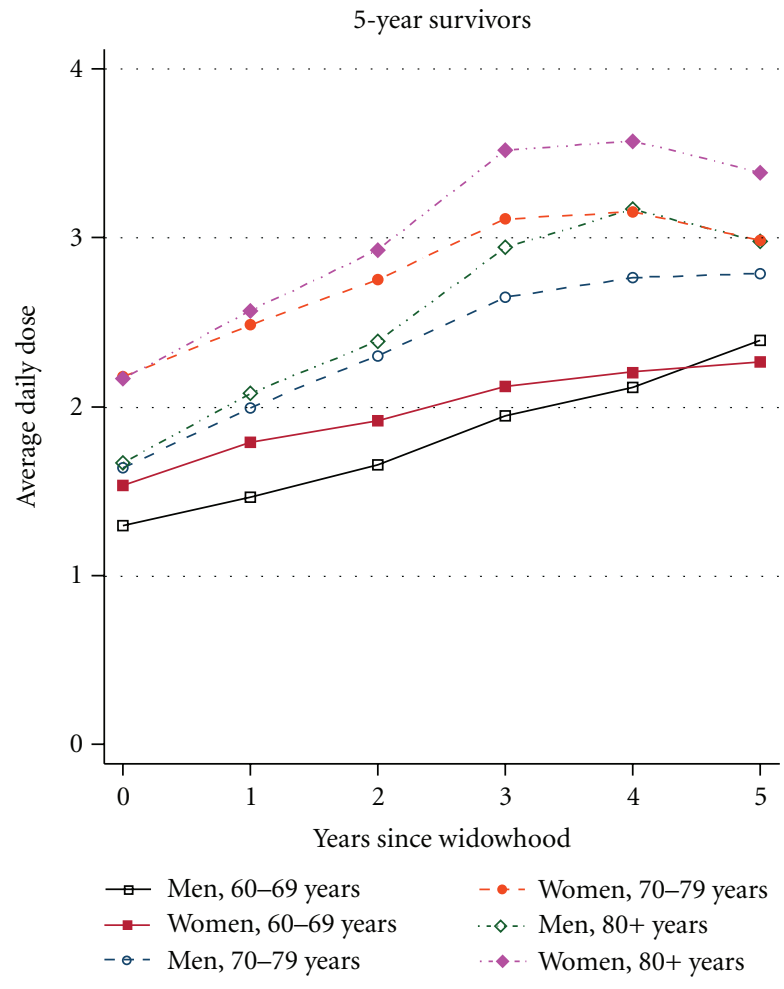

(b)

Figure 3: All-cause medication use among 3- and 5-years survivors.

unaltered when the change in medication use 1 year before and after widowhood was evaluated among users only or when medication use was estimated for several therapeutic subgroups (e.g., psycholeptics, psychoanaleptics, cardiac therapy, diuretics, beta blocking agents, calcium channels blockers, and agents acting on rennin-angiotensin system) (data available on request).

\section{Discussion}

The present study aimed at comparing medication and primary healthcare use around the time of widowhood among men versus same-aged women. It showed that all-cause and major medication use, as well as primary healthcare use, increased shortly after conjugal loss, as well as in the 3-4 years following spousal bereavement, and remained constant or slightly decreased thereafter. The trajectories of all-cause and system-specific medication use and the annual number of GP visits over the period from 1 year before and up to 5 years after conjugal loss were similar in men and women. Therefore, we found little support for the hypothesis that widowers reduce medication use or visits to GPs, while widows utilize healthcare services to a degree similar to that of a preloss level. The increasing number of GP visits and allcause and system-specific medication use is likely to reflect the effect of age on the healthcare use rather than the effect of spousal loss.

Compared to the growing research on widowhoodmortality association, the number of studies that investigated the underlying mechanisms responsible for poor outcomes following the death of a spouse, and, in particular, the reasons why widowers fare worse than widows is less extensive. Thompson and colleagues revealed that although within 2-month period bereaved persons aged 55-83 years had increased medication use, more severe illness, and worse perceived general health, the number of physician visits and hospitalizations was similar in bereaved and nonbereaved groups [29]. The authors found no sex differences in the increased risk of medication use, although women were more likely to report new and/or deteriorated health compared with men regardless of marital status. Another US study found that old-aged widowed persons with traumatic grief were less likely to use all types of healthcare services within 2 months after spouse's death compared with the bereaved subjects without traumatic grief [28]. Williams found that widowhood increased the risk of having unhealthy lifestyle behavior, developing a serious illness, and reporting worse general health only among those widowed persons who had a substantial decline in the frequency of health reminders [25]. Transition to widowhood was found to increase the first-time use of domiciliary care services among 70 years and over participants of the British Household Panel Survey [38]. However, no sex differences in the change of healthcare use associated with widowhood were reported in most studies. A recent study among Medicare beneficiaries showed substantial drop in obtaining preventive services, such as diabetic monitoring, cancer screening, and vaccination, but 
considerable increase in the rates of preventable hospitalization and early readmissions [26]. Like in our study, there were little gender differences in obtaining preventive services, although widowed men had substantially higher rates of preventable hospitalizations and early readmissions than widows and no long-term detrimental effects of spousal loss on individual abilities to obtain preventive healthcare services were indicated [26].

The present study adds to the previous research evidence in Denmark and other Nordic countries [39, 40] showing that all-cause and system-specific medication use was more frequent and the average daily dose for all-cause and nervous system medications was higher among women compared with same-aged men. The average daily use of respiratory medications was slightly higher among men, whereas no sexspecific pattern was observed for ATC-C medication use.

A major strength of this study is the size, representativeness, and completeness of the Danish register data and its longitudinal nature that enabled us to examine sex differences in medication and primary healthcare use over a longer follow-up period after the event. Because the data on medication and primary healthcare use were obtained for all individuals from the $5 \%$ population sample and the twin population aged $60+$ by January 1, 1996 and who became widowed in the period from 1996 to 2003, there was no room for selection bias due to nonparticipation or loss to followup inherent in longitudinal surveys. The present study had a sufficiently large sample size and, thus, good power to detect sex-specific pattern in health behaviors before and after spousal bereavement.

The analysis of medication use and number of GP visits over the follow-up years reflects both the effect of age on the health care utilization and the effect of conjugal bereavement. However, it is unlikely to bias the analysis of male-female differences in healthcare utilization before and after spouse's death. Clearly, our findings may be country-specific and may not be generalizable to other settings. It has been found that Sweden and Denmark have greater gender equality in the division of household labor compared with Greece or Spain [41]. Possibly, men in northern EU countries depend less on their wives for regulating health behaviors than in the more traditional southern EU. Further research should attempt to replicate this study in other populations where register data are available.

\section{Conclusions}

This study shows no sex difference in the trajectories of medication and primary healthcare use within 1 year before and up to 4 years after spouse's death. Therefore, this Danish study found no support for the hypothesis that reduced medication and primary healthcare use contribute to the explanation of more adverse health outcomes after conjugal loss in men compared with women in Denmark.

\section{Acknowledgments}

The authors thank Dr. Henrik Stovring for his very helpful consultations on pharmacoepidiomiolgical methods used in this study. This study was supported by research Grants from the National Institute on Aging (NIA-PO1-AG08761, NIAP01-AG031719), and the VELUX Foundation.

\section{References}

[1] M. Stroebe, H. Schut, and W. Stroebe, "Health outcomes of bereavement," Lancet, vol. 370, no. 9603, pp. 1960-1973, 2007.

[2] C. L. Hart, D. J. Hole, D. A. Lawlor, G. D. Smith, and T. F. Lever, "Effect of conjugal bereavement on mortality of the bereaved spouse in participants of the Renfrew/Paisley study," Journal of Epidemiology and Community Health, vol. 61, no. 5, pp. 455460, 2007.

[3] P. Martikainen and T. Valkonen, "Mortality after the death of a spouse: rates and causes of death in a large Finnish cohort," American Journal of Public Health, vol. 86, no. 8 I, pp. 10871093, 1996.

[4] J. Kaprio, M. Koskenvuo, and H. Rita, "Mortality after bereavement: a prospective study of 95,647 widowed persons," American Journal of Public Health, vol. 77, no. 3, pp. 283-287, 1987.

[5] F. Elwert and N. A. Christakis, "The effect of widowhood on mortality by the causes of death of both spouses," American Journal of Public Health, vol. 98, no. 11, pp. 2092-2098, 2008.

[6] C. Schaefer, C. P. Quesenberry, and S. Wi, "Mortality following conjugal bereavement and the effects of a shared environment," American Journal of Epidemiology, vol. 141, no. 12, pp. 1142-1152, 1995.

[7] A. Erlangsen, B. Jeune, U. Bille-Brahe, and J. W. Vaupel, "Loss of partment and suicide risks among oldest old: a populationbased register study," Age and Ageing, vol. 33, no. 4, pp. 378383, 2004.

[8] P. C. Krochalk, Y. Li, and I. Chi, "Widowhood and selfrated health among Chinese elders: the effect of economic condition," Australasian Journal on Ageing, vol. 27, no. 1, pp. 26-32, 2008.

[9] D. Umberson, C. B. Wortman, and R. C. Kessler, "Widowhood and depression: explaining long-term gender differences in vulnerability," Journal of Health and Social Behavior, vol. 33, no. 1, pp. 10-24, 1992.

[10] N. Goldman, S. Korenman, and R. Weinsteins, "Marital status and health among the elderly," Social Science and Medicine, vol. 40, no. 12, pp. 1717-1730, 1995.

[11] E. Nihtilä and P. Martikainen, "Institutionalization of older adults after the death of a spouse," American Journal of Public Health, vol. 98, no. 7, pp. 1228-1234, 2008.

[12] L. Li, J. Liang, A. Toler, and S. Gu, "Widowhood and depressive symptoms among older Chinese: do gender and source of support make a difference?" Social Science and Medicine, vol. 60, no. 3, pp. 637-647, 2005.

[13] E. Nihtilá and P. Martikainen, "Why older people living with a spouse are less likely to be institutionalized: the role of socioeconomic factors and health characteristics," Scandinavian Journal of Public Health, vol. 36, no. 1, pp. 3543, 2008.

[14] M. Stroebe, W. Stroebe, and H. Schut, "Gender differences in adjustment to bereavement: an empirical and theoretical review," Review of General Psychology, vol. 5, no. 1, pp. 62-83, 2001.

[15] M. S. Stroebe and W. Stroebe, "Who suffers more? Sex differences in health risks of the widowed," Psychological Bulletin, vol. 93, no. 2, pp. 279-301, 1983.

[16] F. Elwert and N. A. Christakis, "Widowhood and race," American Sociological Review, vol. 71, no. 1, pp. 16-41, 2006. 
[17] S. A. Onrust and P. Cuijpers, "Mood and anxiety disorders in widowhood: a systematic review," Aging and Mental Health, vol. 10, no. 4, pp. 327-334, 2006.

[18] E. Agerbo, "Midlife suicide risk, partner's psychiatric illness, spouse and child bereavement by suicide or other modes of death: a gender specific study," Journal of Epidemiology and Community Health, vol. 59, no. 5, pp. 407-412, 2005.

[19] C. Tomassini, A. Rosina, F. C. Billari, A. Skytthe, and K. Christensen, "The effect of losing the twin and losing the partner on mortality," Twin Research, vol. 5, no. 3, pp. 210$217,2002$.

[20] K. Hemminki and X. Li, "Lifestyle and cancer: effect of widowhood and divorce," Cancer Epidemiology Biomarkers and Prevention, vol. 12, no. 9, pp. 899-904, 2003.

[21] Ø. Kravdal, "The impact of marital status on cancer survival," Social Science and Medicine, vol. 52, no. 3, pp. 357-368, 2001.

[22] D. Umberson, "Family status and health behaviors: social control as a dimension of social integration," Journal of Health and Social Behavior, vol. 28, no. 3, pp. 306-319, 1987.

[23] D. R. Shahar, R. Schultz, A. Shahar, and R. R. Wing, "The effect of widowhood on weight change, dietary intake, and eating behavior in the elderly population," Journal of Aging and Health, vol. 13, no. 2, pp. 186-199, 2001.

[24] S. Lee, E. Cho, F. Grodstein, I. Kawachi, F. B. Hu, and G. A. Colditz, "Effects of marital transitions on changes in dietary and other health behaviours in US women," International Journal of Epidemiology, vol. 34, no. 1, pp. 69-78, 2005.

[25] K. Williams, "The transition to widowhood and the social regulation of health: consequences for health and health risk behavior," Journals of Gerontology. Series B, vol. 59, no. 6, pp. S343-S349, 2004.

[26] L. Jin and N. A. Chrisatakis, "Investigating the mechanism of marital mortality reduction: the transition to widowhood and quality of health care," Demography, vol. 46, no. 3, pp. 605625, 2009.

[27] D. Carr, "Gender, Preloss Marital Dependence, and Older Adults' Adjustment to Widowhood," Journal of Marriage and Family, vol. 66, no. 1, pp. 220-235, 2004.

[28] H. Prigerson, G. Silverman, S. Jacobs, P. Maciejewski, S. Kasl, and R. Rosenheck, "Traumatic grief, disability and the underutilization of health services: a preliminary look," Prim Psychiatry, vol. 8, pp. 61-69, 2001.

[29] L. W. Thompson, J. N. Breckenridge, D. Gallagher, and J. Peterson, "Effects of bereavement on self-perceptions of physical health in elderly widows and widowers," Journals of Gerontology, vol. 39, no. 3, pp. 309-314, 1984.

[30] G. R. Lee, A. DeMaris, S. Bavin, and R. Sullivan, "Gender differences in the depressive effect of widowhood in later life," Journals of Gerontology. Series B, vol. 56, no. 1, pp. S56-S61, 2001.

[31] T. J. Iwashyna and N. A. Christakis, "Marriage, widowhood, and health-care use," Social Science and Medicine, vol. 57, no. 11, pp. 2137-2147, 2003.

[32] A. Skytthe, K. Kyvik, N. V. Holm, J. W. Vaupel, and K. Christensen, "The Danish Twin Registry: 127 Birth cohorts of twins," Twin Research, vol. 5, no. 5, pp. 352-357, 2002.

[33] C. B. Pedersen, H. Gøtzsche, J. Ø. Møller, and P. B. Mortensen, "The Danish Civil Registration System. A cohort of eight million persons," Danish Medical Bulletin, vol. 53, no. 4, pp. 441-449, 2006.

[34] T. F. Andersen, M. Madsen, J. Jørgensen, L. Mellemkjær, and J. H. Olsen, "The Danish National Hospital Register: a valuable source of data for modern health sciences," Danish Medical Bulletin, vol. 46, no. 3, pp. 263-268, 1999.
[35] K. Christensen, A. Wienke, A. Skytthe, N. V. Holm, J. W. Vaupel, and A. I. Yashin, "Cardiovascular mortality in twins and the fetal origins hypothesis," Twin Research, vol. 4, no. 5, pp. 344-349, 2001.

[36] K. Christensen, O. Basso, K. O. Kyvik et al., "Fecundability of female twins," Epidemiology, vol. 9, no. 2, pp. 189-192, 1998.

[37] WHO ATC: Anatomical Therapeutic Chemical classification system, "WHO Collaborating Center for Drug Statistics 2009," WHO, Oslo, Norway.

[38] K. Glaser, C. Tomassini, F. Racioppi, and R. Stuchbury, "Marital disruptions and loss of support in later life: a longitudinal study of the United Kingdom," European Journal of Ageing, vol. 3, no. 4, pp. 207-216, 2006.

[39] C. M. Roe, A. M. McNamara, and B. R. Motheral, "Genderand age-related prescription drug use patterns," Annals of Pharmacotherapy, vol. 36, no. 1, pp. 30-39, 2002.

[40] T. Jörgensen, S. Johansson, A. Kennerfalk, M. A. Wallander, and W. K. Svärdsudd, "Prescription drug use, diagnoses, and healthcare utilization among the elderly," Annals of Pharmacotherapy, vol. 35, no. 9, pp. 1004-1009, 2001.

[41] K. Hank and H. Jürges, "Gender and the division of household labor in older couples: a European perspective," Journal of Family Issues, vol. 28, no. 3, pp. 399-421, 2007. 


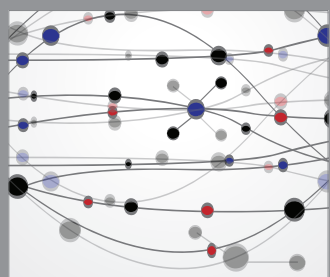

The Scientific World Journal
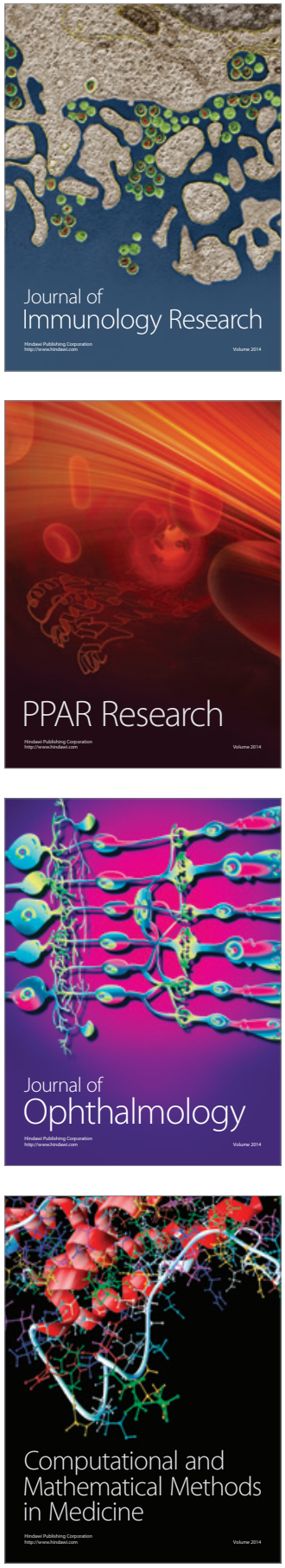

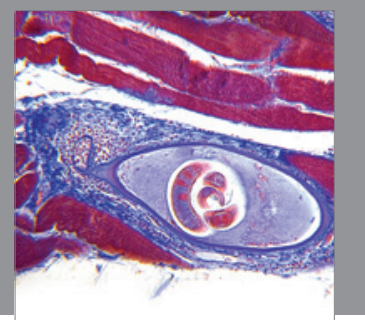

Gastroenterology

Research and Practice
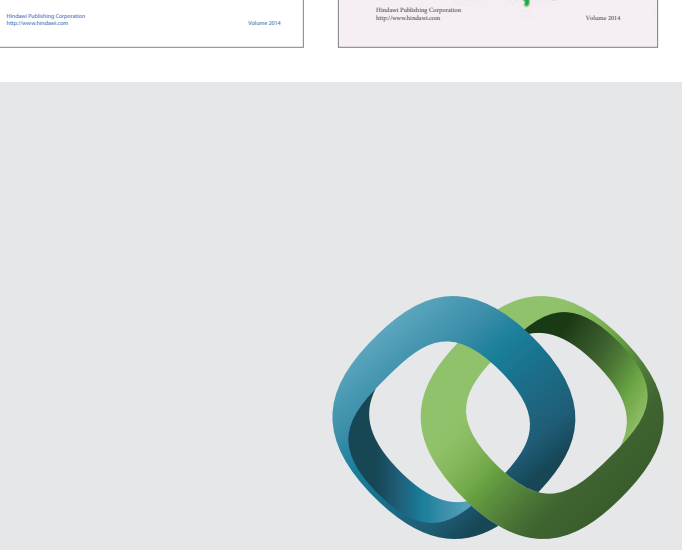

\section{Hindawi}

Submit your manuscripts at

http://www.hindawi.com
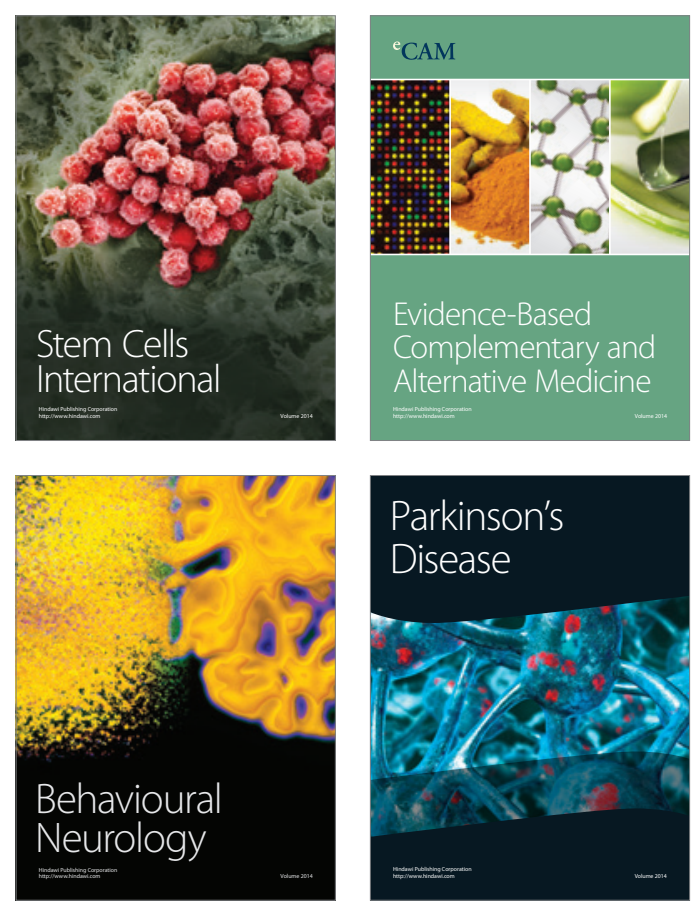

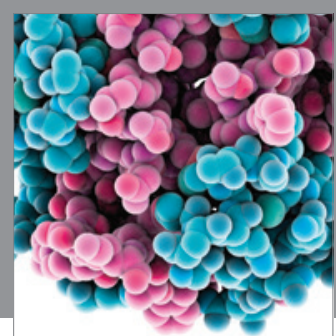

Journal of
Diabetes Research

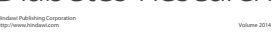

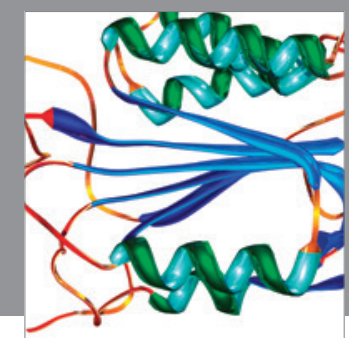

Disease Markers
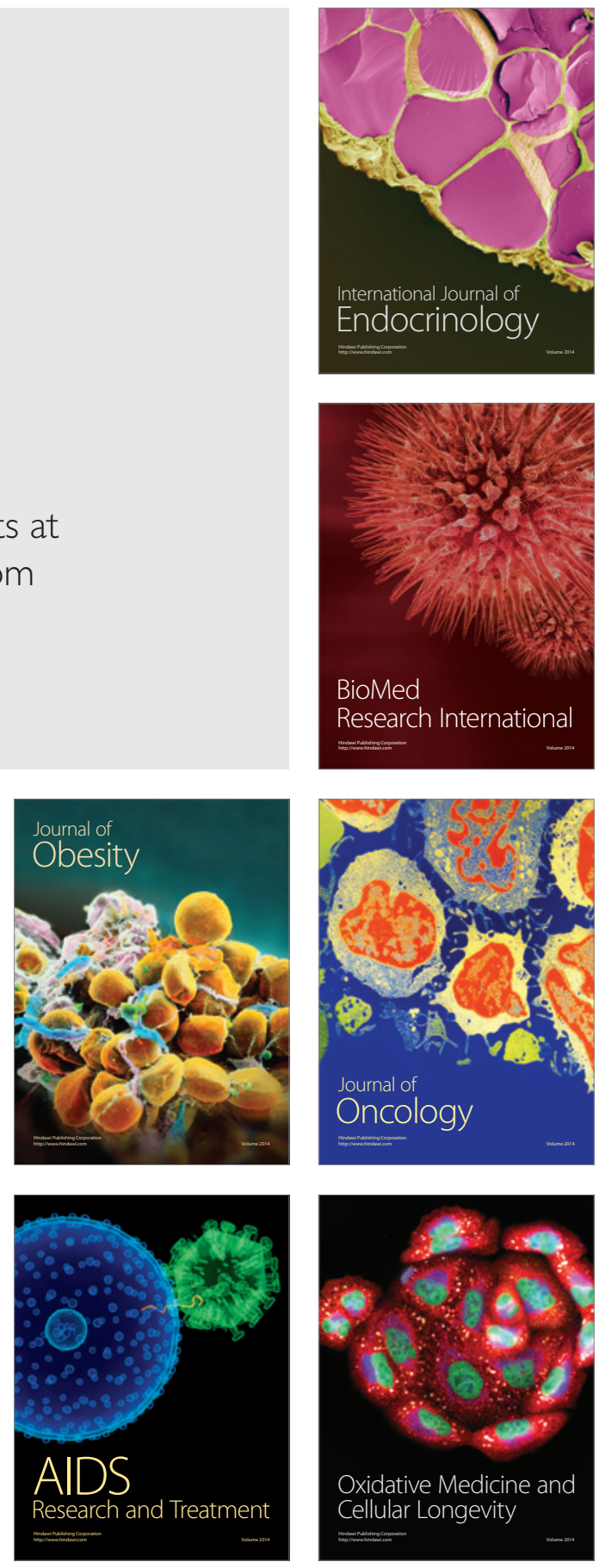